\title{
A Study of the Parameters Influencing Liquid Fuel Burning Rates
}

\author{
CHRISTOPHER MEALY, MATTHEW BENFER, and DAN GOTTUK \\ Hughes Associates Inc. \\ 3610 Commerce Drive, Suite 817 \\ Baltimore, MD 21227 USA
}

\begin{abstract}
An understanding of the mass burning rate of a fuel and the factors affecting this rate is paramount when assessing the hazards associated with a liquid fuel spill/pool scenario. To date, the vast majority of mass burning rate data originate $[1,2]$ from liquid fuel fire scenarios where the fuel layer is 'deep'. However, recent studies [3,4] have shown that, for thin fuel layer scenarios, the maximum mass burning rate achieved is on the order of one-fifth that presented for these 'deep' scenarios. This study investigates the factors affecting the mass burning rate of several different liquid fuels using both fixed area and unconfined fire scenarios. A test program comprised of over 500 small- and large-scale tests was conducted on various substrates using various fuels. The results of the study demonstrate a dependence of the mass burning rate on both duration of fuel supply and substrate, among others. Correlations were developed to modify the peak mass burning rates as a function of fuel supply duration (which can be depth). The impact of substrate relative to the thermal properties of the substrate is also discussed.
\end{abstract}

KEYWORDS: liquid fuels, mass burning rates, substrate effects, fuel depth effects.

\section{NOMENCLATURE LISTING}

$\begin{array}{llll}\dot{m}^{\prime \prime} & \text { mass burning rate per unit area }\left(\mathrm{g} / \mathrm{s} \cdot \mathrm{m}^{2}\right) & \text { Greek } & \\ k & \text { extinction coefficient } & \beta & \text { mean beam length corrector } \\ D & \text { diameter }(\mathrm{m}) & \delta & \text { depth }(\mathrm{mm}) \\ C_{\delta} & \text { depth coefficient } & \sigma & \text { surface tension }(\mathrm{mN} / \mathrm{m}) \\ & & \text { subscript } & \\ & & \infty & \text { maximum }\end{array}$

\section{INTRODUCTION}

To date, most liquid fuel fire studies have focused on characterizing the steady-state burning rates of liquid fuels. This characterization generally requires the presence of a relatively deep fuel layer in order to be able to establish and maintain a steady-state temperature gradient within the fuel. The majority of the studies conducted utilized fixed area pans constructed from either steel or concrete and a continuous-feed fuel supply system to maintain a constant fuel level within the confined area. These tests generally required the burning of significant quantities of fuel for relatively long periods of time. In the event that the release of a fuel results in a fuel depth less than that required to achieve steady-state burning, an understanding of the parameters affecting the development of the mass burning rate becomes necessary. Gottuk et al. [3] and Putorti [4] both demonstrated that the burning rates achieved from fuel spill scenarios with spill depths on the order of $1 \mathrm{~mm}$ are approximately one-fifth that measured in the deep pool fire. Despite this fact, there has been little systematic testing to understand the impacts of fuel layer depth and substrate on fire development. In response to this, a research program [5] was undertaken with the purpose of expanding the fundamental understanding of fuel spill fire dynamics. This paper focuses on the mass burning rate findings of this research. The objective of this paper is to identify and characterize the impacts of both duration of fuel supply and substrate on the mass burning rate of a liquid fuel.

\section{APPROACH}

The objectives of this research were achieved by way of experimental testing combined with empiricalbased analyses. A summary of the tests conducted and the rationale for their execution is provided in Table 1. In this study, a wide variety of liquids and spill substrates were evaluated. The selection of these liquids and substrates was based upon their prevalence and relevancy in real-world fire scenarios. The mass 
burning rates of four different fuels were evaluated, including gasoline, kerosene, denatured alcohol, and nheptane. Gasoline and kerosene were selected due to their prevalence and the fact that they represent a flammable and combustible multi-constituent fuel, respectively. The denatured alcohol represents a common alcohol fuel as opposed to only testing hydrocarbon based fuels. The n-heptane was selected because it is a pure fuel that can be used for direct comparison to literature data. A total of 7 spill substrates were considered: 4 concrete finishes, 2 wood flooring materials, a vinyl flooring material, and a base grade carpet with pad. More specifically, these substrates included coated concrete, two types of hard-trowelfinished concrete, brushed concrete, $14.7 \mathrm{~mm}(0.58 \mathrm{in}$.) plywood, $14.7 \mathrm{~mm}$ (0.58 in.) oriented-strand board (OSB), and vinyl sheet flooring over plywood. These substrates are common types of flooring in residential, commercial, and industrial applications.

Table 1. Summary of tests conducted.

\begin{tabular}{|l|l|}
\hline Test series name & Rationale for testing \\
\hline Pan fires & Benchmark and to characterize impact of fuel depth on burning rate \\
\hline Diked fires & Characterize impact of substrate on fuel burning rate \\
\hline Continuous spill fires & Characterize the steady state burning rate of spill fires \\
\hline
\end{tabular}

\section{EXPERIMENTAL SET-UP}

All tests described in this section were conducted beneath calibrated hood calorimeters capable of performing oxygen consumption calorimetry to within $\pm 5 \%$ of a known fire size. The pan fires conducted in this research utilized three different size fuel pans and evaluated seven different fuel depths ranging from 1-40 mm (0.04-1.6 in.). The range of fuel depths evaluated was based upon the fact that unconfined spill depths are generally on the order of $1 \mathrm{~mm}(0.04 \mathrm{in}$.) in depth [6] and some of the historic burning rate data was collected for fuel depths on the order of $40 \mathrm{~mm}$ (1.6 in.). The burning of these various fuel layers was evaluated on both steel and water substrates. The fuel pans were square in geometry with side lengths of $0.3 \mathrm{~m}$ (12 in.), $0.6 \mathrm{~m}$ (24 in.), and $1.2 \mathrm{~m}$ (48 in.) with an internal vertical lip height of $6.4 \mathrm{~cm}$ (2.5 in.). The pan sizes chosen were designed such that their equivalent diameters resulted in burning modes that ranged from radiative/optically thin $(0.2<D<1.0 \mathrm{~m})$ to radiative/optically thick $(D>1 \mathrm{~m})$ [7]. As indicated, the fuels evaluated in this test series included gasoline, kerosene, denatured alcohol, and n-heptane. Instrumentation used in the pan fire test series included hood calorimetry, mass loss via load cell, incident heat flux to the base of the fire, and temperature. Once the pan was filled to the specified depth, the fuel was ignited using a propane torch. The time of sustained ignition was considered as the start of all tests. The flame extinguishment time was also recorded at the end of each test. Substrate temperature was controlled for all tests to ensure repeatability between testing. In the case of tests conducted on water substrates, fresh water was used in each test. The depth of water used in all water substrate testing was $25.4 \mathrm{~mm}$ (1 in.) in the test pan.

The diked fires conducted were the same as the pan fires except for the substrates on which the fuels were poured. For these scenarios, fuels were burning atop coated concrete and vinyl as opposed to steel and water. Similar fire areas, fuel depths, instrumentation schemes, fuels, and test procedures were used in the diked fire testing. Substrate temperature was controlled for all tests conducted to ensure repeatability between testing. For vinyl, a combustible substrate, new material was used for each test conducted. It should be noted that in both the $1.2 \mathrm{~m}$ (48 in.) pan and diked fire tests, kerosene was not used due to the inability of the full fuel layer to ignite; instead, denatured alcohol was used for these tests.

In addition to the fixed quantity / fixed area fires described above, a series of continuous spill fires were conducted using both gasoline and denatured alcohol. The purpose of these tests was to provide a thin spill that was continuously maintained in contrast to the small depth, fixed quantity pan and diked fires where the depth of the pool decreased as the fire burned. In these tests, a fixed flow rate of $2.11 / \mathrm{min}(0.55 \mathrm{gpm}) \mathrm{of}$ fuel was delivered to the surface of the smooth concrete substrate. Fuel was delivered to the substrate at a nominal pressure of $34.5 \mathrm{kPa}(5 \mathrm{psi})$ through a $12.7 \mathrm{~mm}(0.5 \mathrm{in}$.) orifice pipe that was flush to the surface and imbedded in the center of the concrete pad, such that the fuel bubbled out like a ground level spring. Once fuel started to spread over the substrate, it was ignited and the flow rate of fuel was adjusted such that an equilibrium fire area was sustained for a period of approximately five minutes. After five minutes, the 
fuel flow to the surface was secured and the test was ended. Instrumentation used in these tests included hood calorimetry and substrate temperature measurements collected using both thermal imaging and embedded thermocouples. Substrate temperature was controlled for all tests conducted to ensure repeatability between testing.

\section{EXPERIMENTAL RESULTS}

Due to the large number of tests conducted, it is not possible to present a complete data set within the confines of this paper. However, the results presented herein are representative of those obtained in each test series for the various scenarios evaluated. For a complete presentation of the data set collected in this work the reader is referred to the full report [5]. In general, the coefficient of variance between replicate tests was less than ten percent for heat release rates. Furthermore, the trends observed at a given fire size were found to be true for each of the fire sizes evaluated for the fixed quantity / fixed area scenarios.

\section{Pan and Diked Fires}

The primary variables evaluated in the pan and diked fire testing were geometrical fire size (i.e., equivalent diameter), fuel depth, and fuel substrate. In these test series, a total of three different fire diameters, eight fuel depths, and four fuel substrates were evaluated. Representative plots of the heat release rate per unit area (HRRPUA) illustrating the impacts of each of these variables are provided in Fig. 1. In general, measured fire sizes increased with both pan size and fuel depth and substrate effects were only observed at fuel depths of $2 \mathrm{~mm}$ or less.

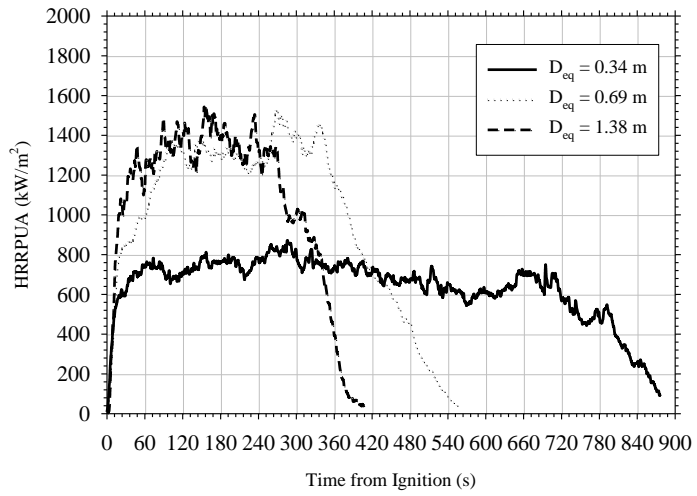

(a)

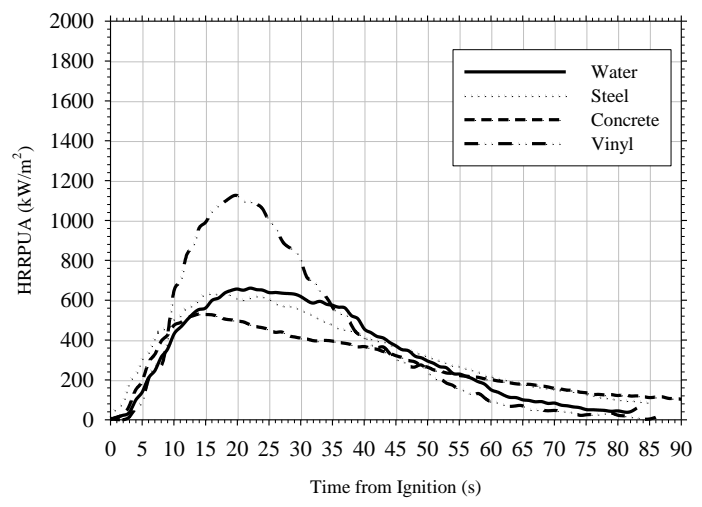

(c)

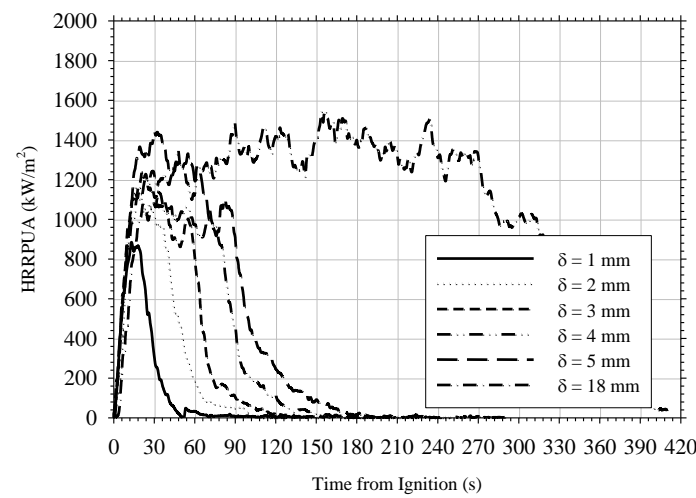

(b)

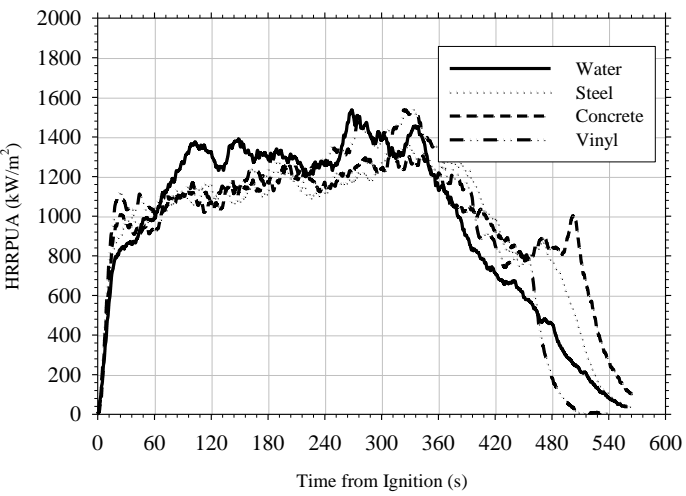

(d)

Fig. 1. Comparison of gasoline heat release rates per unit area as a function of: (a) impact of fire diameter on $1 \mathrm{~mm}$ fuel spills; (b) impact of fuel depth; (c) impact of substrate with a $1 \mathrm{~mm}$ fuel depth; (d) impact of substrate with a $20 \mathrm{~mm}$ fuel depth. 


\section{Continuous Spill Fires}

A total of three continuous spill fire tests were conducted, two using gasoline and one using denatured alcohol. The heat release rates measured for these tests are presented in Fig. 2a and Fig.2b, respectively.

The primary goal of conducting these continuous spill fires was to be able to compare the steady-state heat release rates obtained from various depths, fixed quantity fires to those obtained from a thin fuel layer that is continuously fed. Due to the need to adjust the fuel flow rates during the early stages of the continuouslyfed spill fires, the data collected before the steady-state period was not included when assessing steadystate heat release and mass burning rate data.

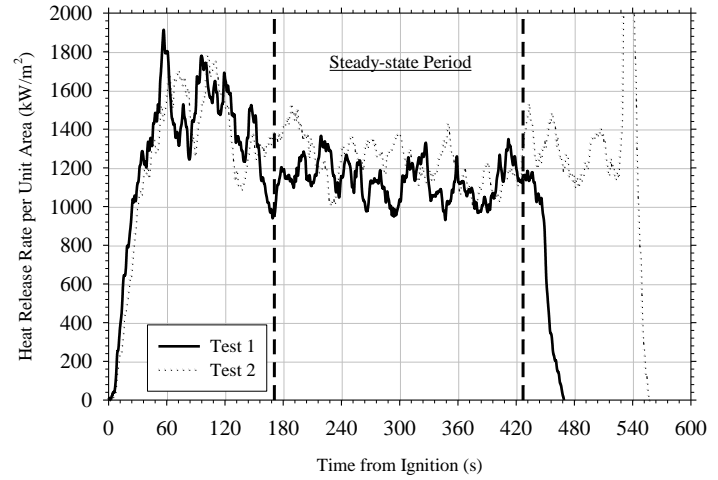

(a)

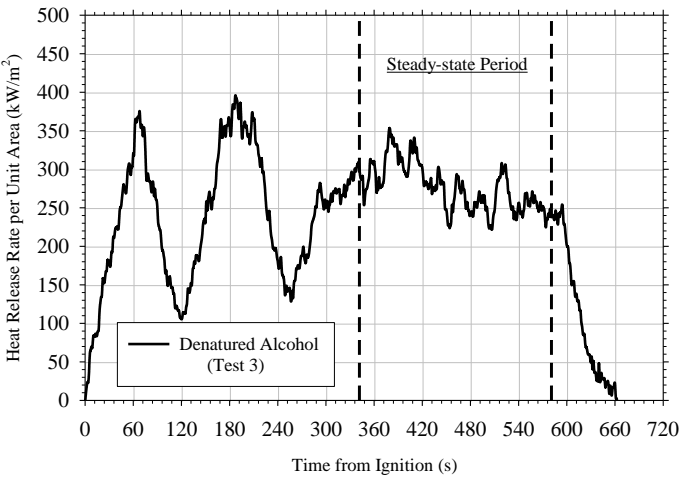

(b)

Fig. 2. Heat release rate per unit area data for continuously-fed: (a) gasoline; (b) denatured alcohol spill fires conducted atop smooth concrete.

\section{ANALYSIS AND DISCUSSION}

To date, the most comprehensive collection of liquid fuel burning rate data has been compiled by Babrauskas [8]. The majority of this data set is now 30-50 years old, which is irrelevant if considering pure fuels. However, when considering multi-constituent fuels (e.g., gasoline, kerosene, etc.) it is reasonable to assume that the components used in these fuels as well as the mixture ratios of these components may have changed with time. Recent surveys of the gasoline in the United States by the Environmental Protection Agency (EPA) suggest that the volatility of gasoline has decreased and that the use of alcohols within gasoline mixtures has increased [9]. Consequently, it is important to verify that the data provided in these references, while technically sound, are still representative of the fuels in use today. The mass burning rates of the fuels evaluated in this study were compared to the data available in the literature to address the potential change due to variations in composition.

Before evaluating multi-component fuels, the burning rate of a pure fuel was evaluated to assess a baseline for the tests conducted. The peak mass burning rate (based on a $10 \mathrm{~s}$ running average) of a $0.093 \mathrm{~m}^{2}$, $20 \mathrm{~mm}$ deep n-heptane pan fire is compared in Fig. 3 to the commonly used, empirically-based correlations [8]. In all cases presented herein, the mass burning rate was calculated using the measured heat release and an effective heat of combustion as shown in Eq. 1.

$$
\dot{m}^{\prime \prime}=\frac{\dot{Q}}{\Delta H_{c, e f f}}
$$

where $\dot{m}^{\prime \prime}\left(\mathrm{g} / \mathrm{s} \cdot \mathrm{m}^{2}\right)$ is the mss burning rate per unit area, $\dot{Q}(\mathrm{~kW})$ is the measured heat release rate, and $\Delta H_{c, e f f}$ is the effective heat of combustion as measured in the ASTM E1354 [10] cone calorimeter test. 


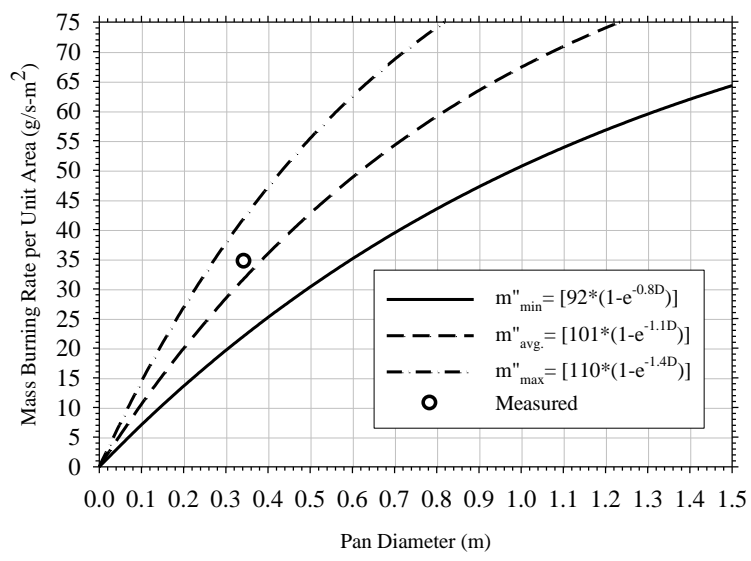

Fig. 3. Comparison of predicted and experimental mass burning rates for a $20 \mathrm{~mm}$ deep, $0.093 \mathrm{~m}^{2}\left(1 \mathrm{ft}^{2}\right)$ n-heptane pan fire.

As expected, given that $\mathrm{n}$-heptane is a pure fuel, the experimental mass burning rate agreed very well with the predictions of the mass burning rate correlations using the fuel property parameters provided in the literature. The experimental mass burning rate was approximately eight percent higher than that predicted using the average fuel property parameters but fell well within the bounding scenarios developed using the parameters provided [8]. Based upon these results, it was concluded that the methodology used to measure fuel mass burning rates in this study was valid and consistent with prior work.

\section{Gasoline Burning Rates}

A total of 85 pan and diked gasoline fires were conducted with fuel layer depths ranging from 1 to $20 \mathrm{~mm}$. A summary of the peak mass burning rates (based on $10 \mathrm{~s}$ running averages) for these tests is provided in Fig. 4. The calculated mass burning rates for gasoline at various fuel layer depths are compared against the empirical correlation developed by Burgess et al. [11] using the maximum mass burning rate and $k \beta$ values provided by Babrauskas [8]. This correlation does not take into account any fuel layer depth/fuel quantity effects.

In general, the peak mass burning rates achieved in the gasoline fires increased as the quantity of fuel available (i.e., fuel depth) increased for these tests. For all fuel depths, except the $1 \mathrm{~mm}$ depths, these values also increased as a function of increasing pool diameter as suggested by the empirical correlation $[8,10]$. However in most cases, the gasoline mass burning rates measured in this study were lower than the value predicted by the mass burning rate correlation using the standard input parameters (i.e., $55 \mathrm{~g} / \mathrm{s} \cdot \mathrm{m}^{2}$ and $2.1 \mathrm{~m}^{-1}$ from [8]) and were even lower than the predictions made using the bounding values provided by Babrauskas for gasoline. The $1 \mathrm{~mm}$ fuel depths resulted in an average peak mass burning rate of $16 \mathrm{~g} / \mathrm{s} \cdot \mathrm{m}^{2}$, approximately one-quarter of that predicted by the empirical correlation. These values are consistent with the findings of Putorti [4] who found unconfined gasoline spill fire mass burning rates of $11 \mathrm{~g} / \mathrm{s} \cdot \mathrm{m}^{2}$. For the 5,10 , and $20 \mathrm{~mm}$ fuel depths, the empirical correlation slightly over-predicted the measured mass burning rates; however, the magnitude of the over prediction decreased as fuel depth increased. A summary of the average peak mass burning rates measured in this study, compared to the range of values predicted using the Burgess et al. [10] correlation, is provided in Table 2. 


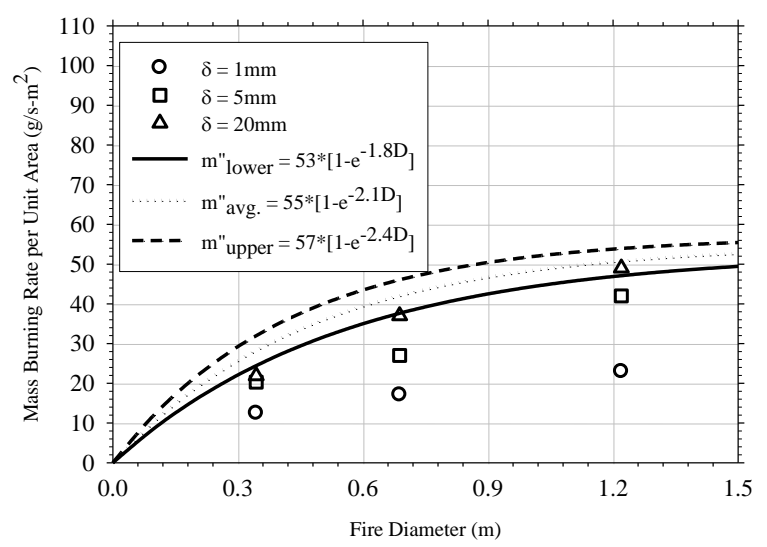

Fig. 4. Measured peak mass burning rates per unit area for all pan and diked gasoline fires conducted compared to empirical burning rate correlation assuming a maximum burning rate of $55 \mathrm{~g} / \mathrm{s} \cdot \mathrm{m}^{2}$ and $\mathrm{k} \beta$ of $2.1 \mathrm{~m}^{-1}$ as suggested by Babrauskas [8].

Table 2. Comparison of measured and predicted gasoline mass burning rates.

\begin{tabular}{|c|c|c|c|c|}
\hline $\begin{array}{c}\text { Equivalent fire } \\
\text { diameter (m) }\end{array}$ & $\begin{array}{l}\text { Fuel depth } \\
\quad(\mathbf{m m})\end{array}$ & $\begin{array}{c}\text { 10 s peak mass } \\
\text { burning rate } \\
\left(\mathrm{g} / \mathbf{s} \cdot \mathbf{m}^{2}\right)\end{array}$ & $\begin{array}{c}\text { Predicted } \\
\text { mass burning } \\
\text { rate }\left(\mathrm{g} / \mathbf{s} \cdot \mathbf{m}^{2}\right)^{\mathrm{a}}\end{array}$ & $\begin{array}{c}\text { Percentage } \\
\text { difference w.r.t. } \\
\text { predicted values }\end{array}$ \\
\hline \multirow{3}{*}{0.34} & 5 & 20 & \multirow{3}{*}{$24-32$} & \multirow{3}{*}{$8-38$} \\
\hline & 10 & 22 & & \\
\hline & 20 & 22 & & \\
\hline \multirow{3}{*}{0.69} & 5 & 29 & \multirow{3}{*}{$38-46$} & \multirow{3}{*}{ 3-37 } \\
\hline & 10 & 30 & & \\
\hline & 20 & 37 & & \\
\hline \multirow[b]{2}{*}{1.38} & 5 & 42 & \multirow{2}{*}{$49-55$} & \multirow[b]{2}{*}{$0-24$} \\
\hline & 20 & 50 & & \\
\hline
\end{tabular}

${ }^{\mathrm{a}}$ Range of values presented is based upon standard deviations provided by Babrauskas for maximum mass burning rates for gasoline $\left(53-57 \mathrm{~g} / \mathrm{s} \cdot \mathrm{m}^{2}\right)$ and $k \beta\left(1.8-2.4 \mathrm{~m}^{-1}\right)$ [8].

As shown in Table 2, the mass burning rate correlation generally over-predicted the measured mass burning rates of gasoline for a range of fuel depths and fire areas. The differences between the measured and predicted mass burning rates ranged from $0-38 \%$ with smaller differences being observed in scenarios with larger quantities of fuel available to burn, which is consistent with the literature in that the data compiled by Babrauskas was primarily based upon testing conducted with deep pool fires and continuous fuel supplies. In Fig. 4, the mass burning rates approach the predicted values as the quantity of fuel (i.e., fuel depth) increases. Furthermore, at the largest fire sizes and fuel quantities, the experimental mass burning rates are trending towards the asymptotic, steady-state value of $55 \mathrm{~g} / \mathrm{s} \cdot \mathrm{m}^{2}$.

Given that at large pool depths (e.g., $20 \mathrm{~mm}$ ), the measured mass burning rate agreed reasonably well with the empirical correlations in the literature at all diameters, Fig. 4 shows that the primary variable impacting peak burning rate was fuel depth. To account for the depth dependence variation between the measured burning rates and the steady-state correlations, a depth coefficient for the existing mass burning rate correlation [10] was developed. In order to accomplish this, the experimental mass burning rates were normalized with respect to the maximum measured mass burning rate for each fuel and correlated to the initial depth of the burning fuel layer. Correlation of the data was accomplished using power law best fits which were calculated for the minimum, average, and maximum data measured for the varying fuel depths. An example of this approach is shown in Fig. 5 which can be used to calculate the depth coefficient to be multiplied by the maximum mass burning rate for a specific fuel in order to obtain a mass burning rate that is both fuel depth and spill area specific (i.e., equivalent diameter). For example, the general form of the mass burning rate per unit area as a function of fuel spill/pool diameter, $D$, and fuel depth, $\delta$, is given as 
$\dot{m}^{\prime \prime}(D, \delta)=C_{\delta}\left(\dot{m}_{\infty}^{\prime \prime}\left[1-e^{-k \beta D}\right]\right)$

where $C_{\delta}$ is the depth coefficient derived from the curve fit shown in Fig. 5, $\dot{m}_{\infty}^{\prime \prime}$ is the maximum mass burning rate of the fuel, $k \beta$ is the product of the extinction coefficient and the mean beam length corrector, and $D$ is the equivalent diameter of the spill/pool. Further discussion of this depth coefficient is provided in the full report on this testing [5].

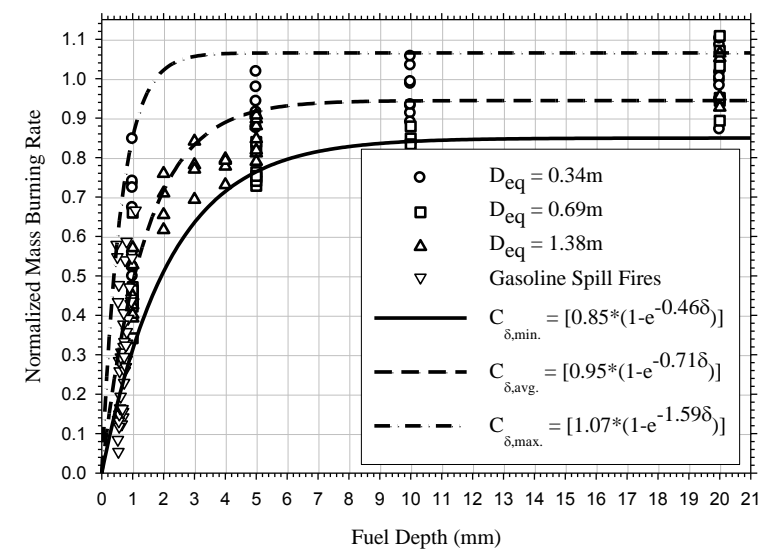

Fig. 5. Summary of normalized peak mass burning rates and best fit curves for all pan and diked gasoline fires conducted.

\section{Kerosene Burning Rates}

Figure 6 compares the measured peak mass burning rates of the kerosene spill fires to the empirical correlations developed by Burgess et al. [10] using the maximum mass burning rate and $k \beta$ values provided by Babrauskas [8]. In the pan and diked fire scenarios evaluated, the average kerosene mass burning rate for a $1 \mathrm{~mm}$ fuel layer was 8.9 and $10.4 \mathrm{~g} / \mathrm{s} \cdot \mathrm{m}^{2}$ for equivalent fire diameters of $0.34 \mathrm{~m}(1.1 \mathrm{ft})$ and $0.69 \mathrm{~m}$ $(2.3 \mathrm{ft})$. These values are approximately one-quarter that predicted by the empirical correlation. For the 5 , 10 , and $20 \mathrm{~mm}$ fuel depths, the empirical correlation slightly over-predicted the mass burning rates; however, the magnitude of the over prediction decreased as fuel depth increased. This finding is consistent with the gasoline data and the maximum mass burning rate values used in the correlations which were primarily developed from deep or continuously fed pan fires. A summary of the peak mass burning rates measured in this study compared to the range of values predicted by the correlation provided in Eq. 2 is given in Table 3.

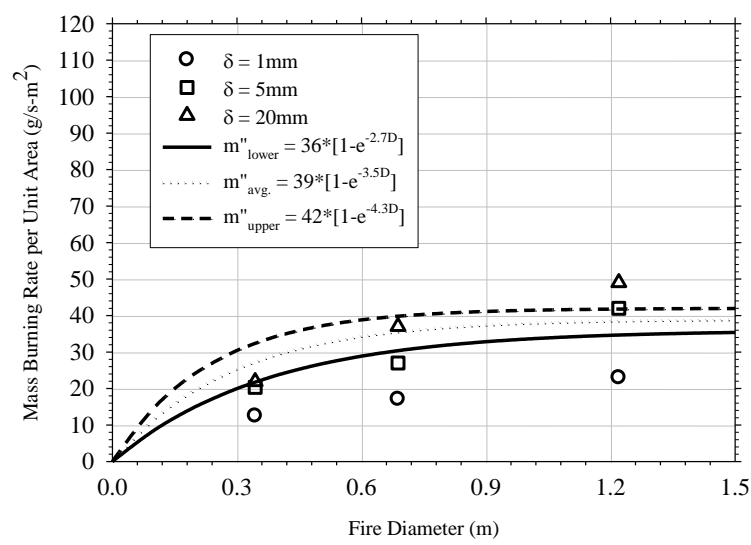

Fig. 6. Measured peak mass burning rates per unit area for all kerosene fires conducted compared to empirical mass rate correlation assuming a maximum burning rate of $39 \mathrm{~g} / \mathrm{s} \cdot \mathrm{m}^{2}$ and $k \beta$ of $3.5 \mathrm{~m}^{-1}$ as suggested by Babrauskas [8]. 
Table 3. Comparison of measured and predicted kerosene mass burning rates.

\begin{tabular}{|c|c|c|c|c|}
\hline $\begin{array}{c}\text { Equivalent fire } \\
\text { diameter }\left(\mathbf{m}^{2}\right)\end{array}$ & $\begin{array}{l}\text { Fuel depth } \\
\text { (mm) }\end{array}$ & $\begin{array}{c}10 \text { s peak mass } \\
\text { burning rate } \\
\left(\mathrm{g} / \mathbf{s} \cdot \mathbf{m}^{2}\right)\end{array}$ & $\begin{array}{l}\text { Range of predicted } \\
\text { mass burning rates } \\
\left(\mathrm{g} / \mathrm{s} \cdot \mathbf{m}^{2}\right)^{\mathrm{a}}\end{array}$ & $\begin{array}{l}\text { Maximum } \\
\text { percentage } \\
\text { difference }^{b}\end{array}$ \\
\hline \multirow{3}{*}{0.344} & 5 & 17 & \multirow{3}{*}{$22-32$} & \multirow{3}{*}{$9-47$} \\
\hline & 10 & 18 & & \\
\hline & 20 & 20 & & \\
\hline \multirow{3}{*}{0.688} & 5 & 22 & \multirow{3}{*}{$30-40$} & \multirow{3}{*}{$(17)^{\mathrm{b}}-45$} \\
\hline & 10 & 26 & & \\
\hline & 20 & 35 & & \\
\hline
\end{tabular}

${ }^{a}$ Range of values presented is based upon standard deviations provided by Babrauskas for maximum mass burning rates for kerosene $\left(36-42 \mathrm{~g} / \mathrm{s} \cdot \mathrm{m}^{2}\right)$ and $k \beta(2.7-4.3)$.

${ }^{\mathrm{b}}$ Values in parentheses indicate the under-prediction of the correlation relative to the experimental mass burning rate.

As shown in 3, the mass burning rate correlation based on literature values [8] generally over-predicted the measured kerosene mass burning rates for the $0.344 \mathrm{~m}(1.1 \mathrm{ft})$ and $0.688 \mathrm{~m}(2.3 \mathrm{ft})$ diameter fires with the exception of the $20 \mathrm{~mm}$ scenario.

An approach similar to that taken in the analysis of the gasoline burning rates was undertaken to develop mass burning rate correlations for kerosene that account for both the effects of varying diameter and varying fuel depth. The experimental mass burning rates were normalized with respect to the maximum mass burning rate measured in the $20 \mathrm{~mm}$ fuel depth scenarios evaluated and correlated to the initial depth of the burning fuel layer. Correlation of the data was accomplished using power law best fits which were calculated for the minimum, average, and maximum data measured for the varying fuel depths. These equations, shown in Fig. 7, were used to calculate a depth coefficient to be multiplied by the diameter dependent maximum mass burning rate for a specific fuel.

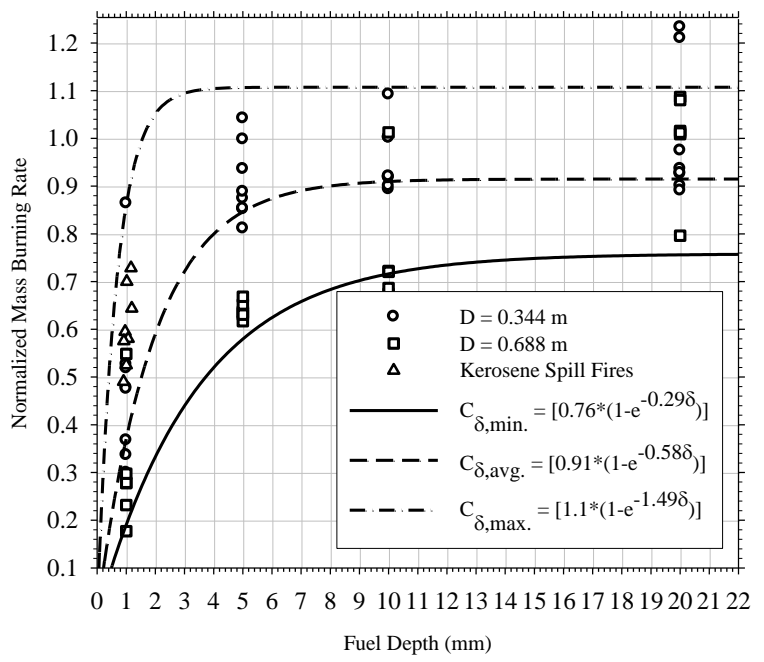

Fig. 7. Summary of normalized peak mass burning rates and best fit curves for all pan and diked kerosene fires conducted.

\section{Denatured Alcohol Burning Rates}

The burning rates from the limited number of denatured alcohol pan fires were compared to data available in the literature. Given that alcohol fires generally produce minimal radiative energy, the mass burning rates for these fuels are often considered as constants. However, recent data described by Babrauskas [8] suggests that the mass burning rates of alcohol fuel fires are diameter dependent and three different burning rate regimes are described. The burning rate regime selected for comparison to the denatured alcohol data 
collected was $22 \mathrm{~g} / \mathrm{s} \cdot \mathrm{m}^{2}$ which was recommended for fire diameters ranging from 0.6 to $3 \mathrm{~m}$ (2 to $10 \mathrm{ft}$ ). This range encompassed all of the fixed area pan fire data presented in Fig. 8.

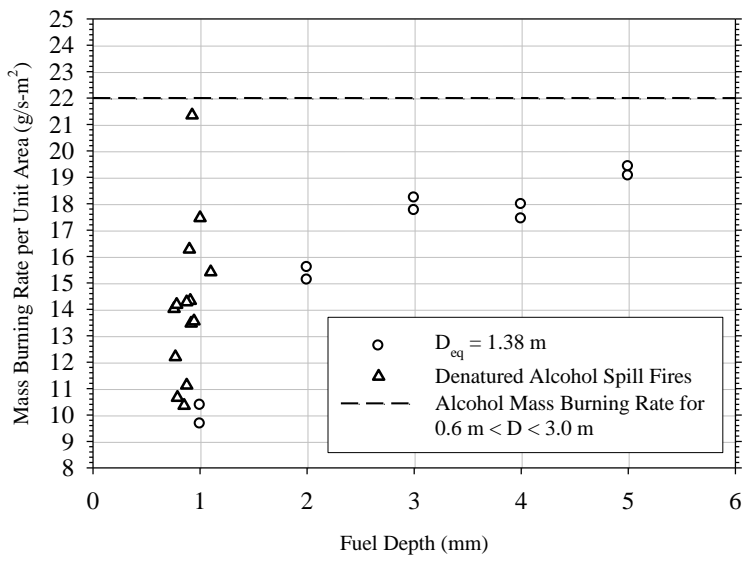

Fig. 8. Comparison of measured peak mass burning rates per unit area for all denatured alcohol pan fires and recommended mass burning rate for alcohol fires with equivalent diameters between 0.6 and $3 \mathrm{~m}$ [8].

The peak mass burning rates measured at the various fuel depths evaluated was consistently less than the recommended mass burning rate for fire diameters ranging from $0.6-3 \mathrm{~m}$. The measured rates ranged from 14-55\% less than the predicted value; the difference decreased with increasing fuel depth. The significant variability in the mass burning rates measured for the spill fire tests is most likely due to the differing substrates on which the tests were conducted. In general, the lowest mass burning rates were measured on the coated concrete substrate with larger values obtained for tests conducted on the wood and vinyl substrates. It should also be noted that similar to what was observed on both the gasoline and kerosene burning rate analyses, as the fuel depth/fuel quantity was increased, the burning rate per unit area was observed to increase.

\section{Variables Impacting Mass Burning Rates}

At the beginning of this study, one hypothesis was that the reduced heat release rates reported for spill fires with relatively thin (i.e., $\leq 2 \mathrm{~mm}$ ) fuel depths were primarily a result of heat losses from the burning fuel to the fuel substrate. In other words, the reduced mass burning rates of the thin fuel depth fires was believed to be primarily a function of the thermal properties of the substrate. This hypothesis was based upon testing conducted by Gottuk et al. [2] and Putorti [3] who found that spill fire burning rates were on the order of one-fifth that of traditional pool fire burning rates. Similar findings were also reported by Garo et al. [12] who attributed the reduced mass burning rates of fuels burning atop a water substrate to the 'heat sink effect' of the water sub-layer. Analysis of these datasets resulted in the conclusion that the differences between the burning rates of thin fuel layers and those reported in the literature, typically deep fuel layers, were potentially due to the differing heat transfer phenomena occurring within a deep fuel layer $(k=0.11 \mathrm{~W} / \mathrm{m} \cdot \mathrm{K})$ versus a thin layer atop a more conductive substrate (i.e., concrete $(k=1.4 \mathrm{~W} / \mathrm{m} \cdot \mathrm{K})$ ). Based upon these data $[3,4,11]$, it was concluded that unconfined fuel spills producing very thin (i.e., $\leq 1 \mathrm{~mm}(0.04 \mathrm{in}$.$) ) fuel depths experience greater heat losses to the substrate, thus reducing the amount of$ heat retained within the burning fuel layer and consequently reducing the fuel mass burning rate [6].

However, further development of this hypothesis resulted in the question that if heat losses were the only factor contributing to the decreased fire size, then it could be expected that fuels burning atop substrates whose thermal properties are comparable to those of a deep pool of fuel would result in fire sizes comparable to those achieved in deep pool burning. For example, consider a wood substrate with a thermal conductivity comparable to that of fuel $\left(k_{\text {wood }}=0.15 \mathrm{~W} / \mathrm{m} \cdot \mathrm{K}\right.$ and $\left.k_{\text {fuel }}=0.19 \mathrm{~W} / \mathrm{m} \cdot \mathrm{K}\right)$. The data reported by Putorti [4] and the measurements in this work indicate that the mass burning rate of a fuel spill fire was in fact significantly reduced even when burning atop a wood substrate, just as observed for more conductive materials. These results suggest that additional factors are contributing to the decreased burning rates commonly observed for thin fuel layer fires. Analyses were performed to characterize the impact of fuel 
substrate and fuel supply duration in order to determine which factors have the greatest influence on the mass burning rate.

\section{Substrate Effects}

The effect of the substrate on the mass burning rate of a fuel is examined in this section. Figure 9 presents the peak mass burning rates from $1 \mathrm{~mm}(0.04 \mathrm{in}$.) deep gasoline fires burning atop four different substrates at three different fire sizes (i.e., pan and diked fire scenarios). The figure also provides comparison of these measured burning rates to the maximum burning rates predicted by the correlation described in Eq. 1. For the gasoline fires evaluated, these comparisons show that the substrate influences the peak mass burning rate achieved. The mass burning rates presented in Fig. 8 increase with equivalent fire diameter and do so in a qualitative manner consistent with the correlation developed in the literature [10].

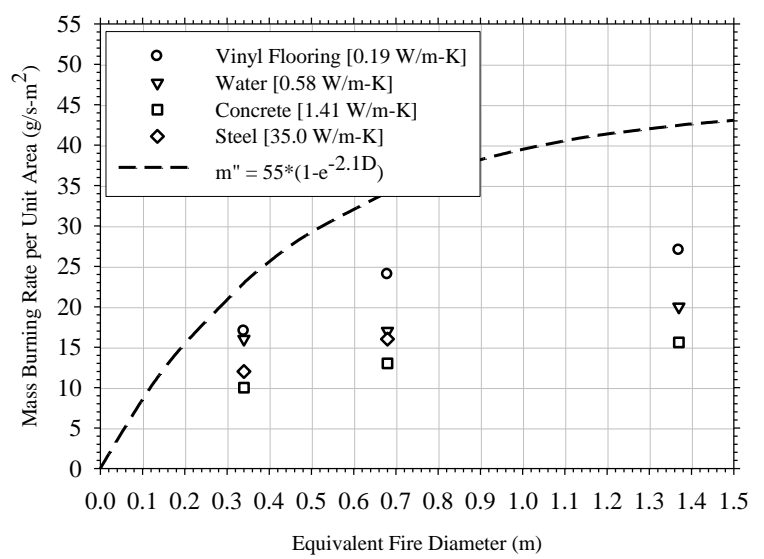

Fig. 9. Comparison of peak mass burning rates per unit area for $1 \mathrm{~mm}$ (0.04 in.) deep gasoline fires atop substrates with various thermal conductivities.

The rank order of the mass burning rates for each fire size were consistent, with the highest burning rates occurring on the vinyl flooring and the lowest on concrete. For the scenarios evaluated, no specific thermal property of the substrates (i.e., thermal conductivity, thermal inertia, thermal effusivity, and thermal diffusivity) could be directly correlated to the rank order of burning rates. In general, less thermally conductive materials (i.e., vinyl and water) produced mass burning rates higher than those achieved in tests with more thermally conductive substrates (i.e., steel and concrete). However, the ranking of mass burning rates with respect to the thermal conductivity of the substrates was not appropriate when evaluating the cases of the concrete and steel. In these cases the mass burning rates measured on the concrete were consistently lower than those measured on the steel, despite the fact that the thermal conductivity of steel is an order of magnitude larger than that of concrete. This discrepancy may be attributed to the reflectivity of the steel and the resulting re-radiation from the steel substrate to the fuel layer. This reflected heat would then be transferred into the fuel layer, thus raising the mass burning rate of the fuel.

\section{Fuel Supply Duration Effects}

The impact of fuel supply duration was first identified in the fixed area pan and diked results and was confirmed using the data obtained in the continuous spill fire tests. As shown in Fig. 2b, the mass burning rate is a function of fuel depth. As the fuel depth increased, the burning rate (heat release rate) increased. The results indicate that for gasoline depths $\geq 5 \mathrm{~mm}$, the peak mass burning rates achieved are comparable, as shown in Fig. 10 for various area gasoline fuel fires on different substrates. Given that the initial growth rate for the gasoline fires was the same regardless of the initial fuel depth, the curves in Figs. 10 and 2b support the hypothesis that the differences in peak heat release rate are due to the fuel supply being depleted at the smaller depths before steady-state burning was established. 


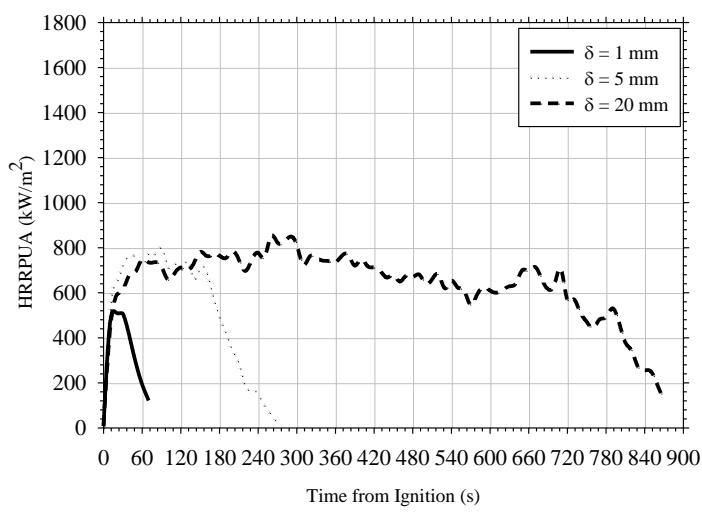

(a)

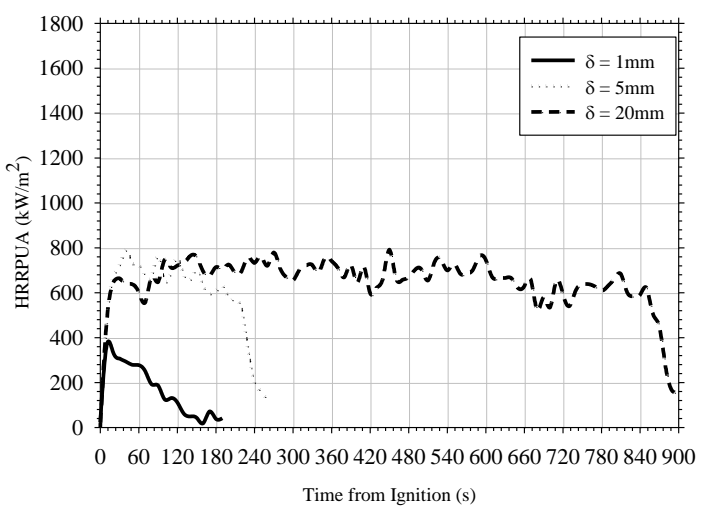

(c)

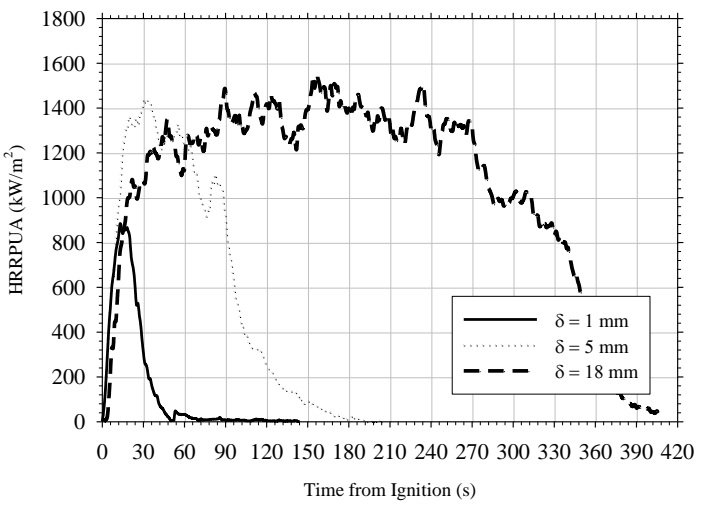

(b)

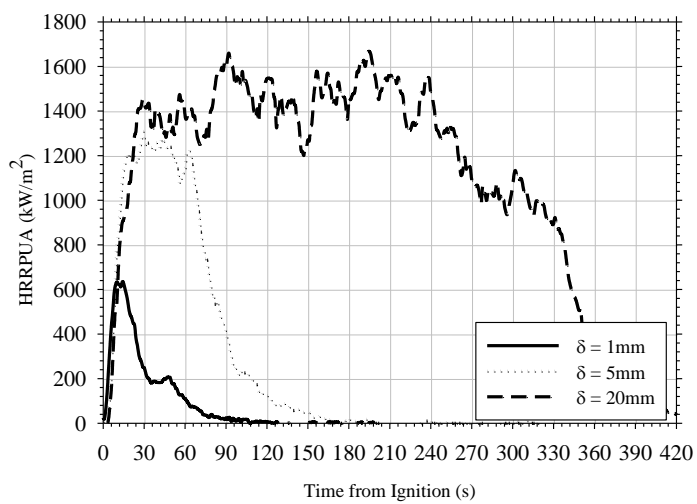

(d)

Fig. 10. Heat release rate per unit area curves for four different fixed fuel quantity, confined fire scenarios: (a) $0.09 \mathrm{~m}^{2}$ - gasoline on water; (b) $1.49 \mathrm{~m}^{2}$ - gasoline on water; (c) $0.09 \mathrm{~m}^{2}$ - gasoline on coated concrete;

(d) $1.49 \mathrm{~m}^{2}$ - gasoline on coated concrete.

The continuous supply, thin layer spill fires further confirmed the hypothesis. For the continuous supply spill fires, a thin layer of fuel (i.e., approximately $1 \mathrm{~mm}$ or less) was maintained over a constant area for an extended period of time. As shown in Fig. 11, the burning rates measured in these scenarios were comparable to those achieved in the deeper pool fires (i.e., $\geq 5 \mathrm{~mm}$ ) and not to those measured for the thin fuel depth, fixed quantity fuel fires. Thus, the fuel supply duration (as dictated by time for continuous spills or by depth for fixed quantity spills/pools) will dictate whether a fire can burn sufficiently long to reach a peak, steady-state mass burning rate (i.e., heat release rate).
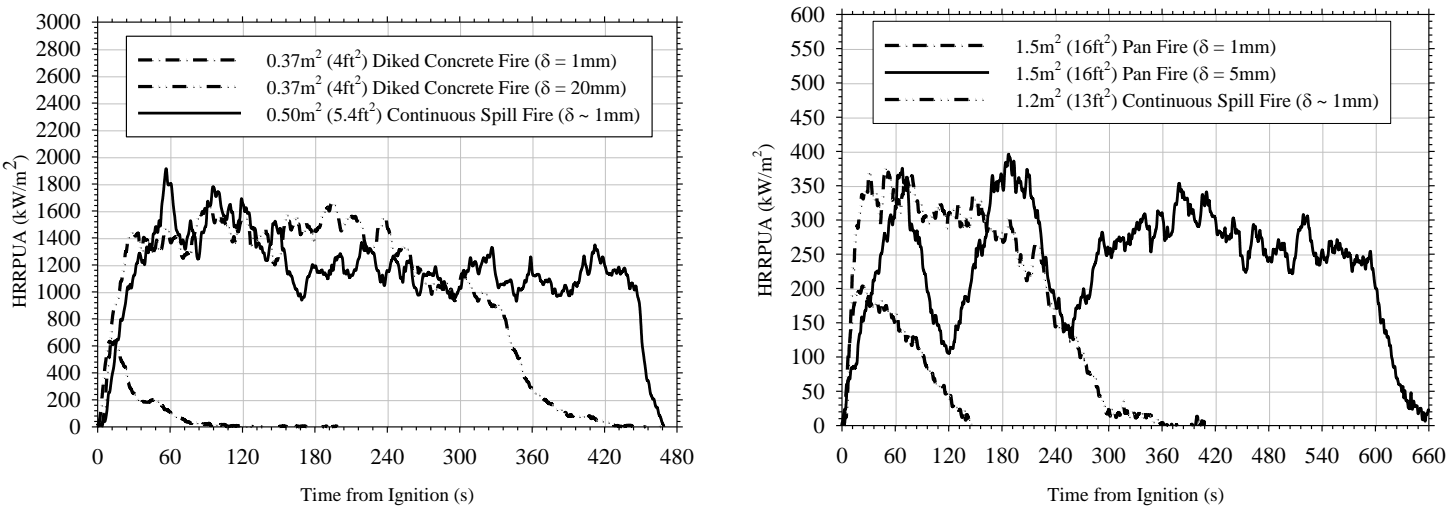

Fig. 11. Comparison of HRRPUA data from confined gasoline fires (left) and denatured alcohol firs (right) of various depths and a continuously-fed, thin $(\sim 1 \mathrm{~mm})$ spill fire. 
In order to accurately describe the burning of a thin fuel spill fire, it is necessary to understand the point at which a spill with a fixed quantity of fuel will stop growing (i.e., at what fraction of fuel consumption is fire growth inhibited), thus initiating the decay of the fire. An analysis of the confined fires (i.e., diked and pan fires) was conducted to examine the fraction of fuel remaining at the time of decay for each fire. This fraction was calculated using the transient total heat released and the measured average effective heat of combustion to calculate mass consumed. At each time step, the total heat released was divided by the heat of combustion and subtracted from the initial mass of fuel present in order to quantify the mass of fuel remaining during each fire. Since some fires did not have a distinct single heat release rate peak before decaying, the time of decay was identified as the time at which the fire reached a heat release rate that was seventy-five percent of its peak during the decay phase of the fire. The results of this analysis are provided in Fig. 12, which correlates the fraction of mass consumed at time of decay to the initial spill depth of the fuel for all fixed area fires. The gasoline and kerosene data presented in Fig. 12 represent the average of multiple tests conducted on four different substrates for a given fire diameter. Standard deviations for the gasoline tests ranged from 0.04 to 0.08 and for the kerosene ranged from 0.04 to 0.12 . Replicate denatured alcohol tests were not conducted; thus statistical analysis could not be performed.

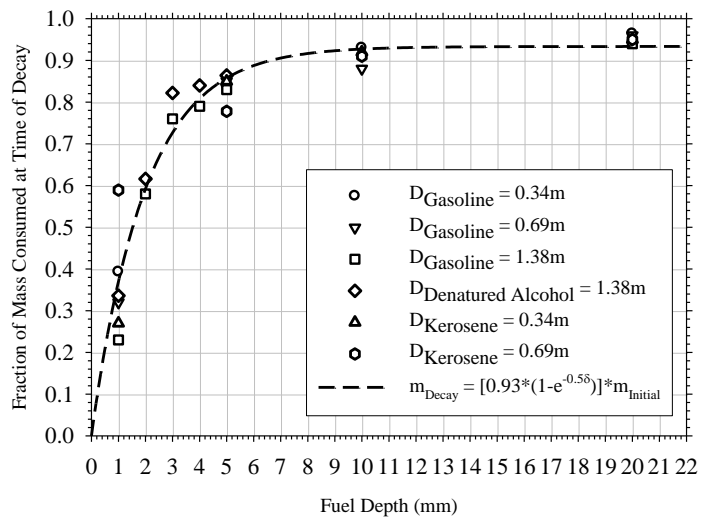

Fig. 12. Correlation of fraction of mass consumed at time of decay for all fixed area fuel fires relative to initial fuel depth.

As shown in Fig. 11, the fraction of mass consumed at the time of decay ranged from 0.23 to 0.96 and generally increased as a function of fuel depth (fuel quantity). In general, the fraction of mass remaining at the time of decay for all fuel types and fire sizes could be correlated to the initial fuel depth relatively well, regardless of fuel type or fire area. For the thinner fuel depths, the fraction of mass consumed at the time of decay ranged from 0.23 to $0.62 \%$. In all other cases (i.e., depths greater than $2 \mathrm{~mm}$ ) the fraction of mass consumed was greater than 0.75 with maximum values as high as $0.96 \%$. In order to further understand the conditions at which the fires ceased to grow, the fraction of mass consumed at the time of decay was used to derive the mass of fuel remaining.

The mass of fuel remaining was used to calculate the average fuel depth at the time of decay. The fuel depths at the time of decay ranged from 0.22 to $0.85 \mathrm{~mm}$ with an average value of $0.55 \mathrm{~mm}$. It should be noted that the average fuel depth of $0.55 \mathrm{~mm}$ assumes a perfectly flat, impermeable surface which in most cases is not representative of real world scenarios. It is likely that it is not the fuel depth of $0.55 \mathrm{~mm}$ that causes the decay but instead it is the inability of the remaining fuel to retain a uniform burning surface atop the substrate (i.e., areas of fuel starvation lead to a smaller surface area of burning thus a smaller heat release rate is measured). Despite this fact, the $0.55 \mathrm{~mm}(0.02 \mathrm{in}$.) fuel depth does provide a strong indication as to when fire growth ceases for the range of fire sizes and fuels considered in this study, and when coupled with an appropriate mass burning rate, could be used to predict the growth and decay of a fixed quantity fuel spill fire.

\section{CONCLUSIONS}

Based upon the testing conducted, in addition to fire diameter, the burning rate of a liquid fuel spill/pool fire is dependent upon several factors including, fuel depth, supply duration, and substrate. Fuel depth was 
identified as a factor because it is directly related to the fuel supply duration for fixed quantity/fixed area fires. For these scenarios, a depth of $5 \mathrm{~mm}$ was established as the minimum depth for which a peak, steadystate mass burning rate comparable to the diameter dependent maximum mass burning rate provided in the literature can be achieved. This was true for steel, water, concrete, and vinyl substrates. At depths less than $5 \mathrm{~mm}$, the peak burning rates were consistently less than the diameter dependent maximum burning rate. The reduction in mass burning rate associated with fixed quantity, approximately $1 \mathrm{~mm}$ fuel depths was on the order of 70-80\%. Based upon the data collected, correlations were developed for both gasoline and kerosene that can be used to predict the reduction in peak mass burning rate as a function of fuel depth. The product of these correlations when coupled with the diameter dependent mass burning rate correlation available in the literature can be used to predict more appropriate mass burning rates for thin fuel layer scenarios. Although this $5 \mathrm{~mm}$ depth criterion was found to be appropriate for all fixed quantity scenarios, the same was not true for continuously-fed fire scenarios. In these scenarios, fuel depths on the order of $1 \mathrm{~mm}$ were maintained while still achieving peak mass burning rates that were comparable to the diameter dependent maximum mass burning rates. These results demonstrated that it is not the depth of fuel that impacts the peak mass burning rate, but that it is the duration of fuel supply. In addition to the impact of fuel supply duration on burning rate, for combustible fuels, specifically, kerosene and diesel the ignitability and flame spread potential of the fuel at thin depths is very small, making the fuel very challenging to ignite and burn in these scenarios.

The second parameter identified as having an impact on the mass burning rate of a fuel was the substrate on which the fuel is burning. However, the influence of the substrate was only found to be significant for fuel depths less than $5 \mathrm{~mm}$. The data collected in this work showed differences in the mass burning rates of $1 \mathrm{~mm}$ depth liquid fuels burning atop surfaces with differing thermal properties. The rank order of the mass burning rates for each fire size were consistent with the highest burning rates occurring on vinyl flooring and the lowest on concrete. For the scenarios evaluated, no specific thermal property of the substrates (i.e., thermal conductivity, thermal inertia, thermal effusivity, and thermal diffusivity) could be directly correlated to the rank order of burning rates. In general, less thermally conductive materials (i.e., vinyl and water) produced mass burning rates higher than those achieved in tests with more thermally conductive substrates (i.e., steel and concrete). However, the ranking of mass burning rates with respect to the thermal conductivity of the substrates was not appropriate when evaluating the case of the concrete and steel. In this case, the mass burning rates measured on the concrete were consistently lower than those measured on the steel despite the fact that the thermal conductivity of steel is an order of magnitude larger than that of concrete. This discrepancy may be attributed to the reflectivity of the steel and the resulting re-radiation from the steel substrate to the fuel layer. This reflected heat would then be transferred into the fuel layer thus raising the mass burning rate of the fuel.

\section{ACKNOWLEDGEMENTS}

This project was supported by Award No. 2008-DN-BX-K168 awarded by the National Institute of Justice, Office of Justice Programs, US Department of Justice. The opinions, findings, and conclusions or recommendations expressed in this publication/program/exhibition are those of the author(s) and do not necessarily reflect those of the Department of Justice.

\section{REFERENCES}

[1] Blinov, V., Khudiakov, G., Diffusion Burning of Liquids, Academiia Nauk, SSSR Doklady, 113:1094-1098, 1957, NTIS No. AD296762, 1961.

[2] Hottel, H., (1959) Certain Laws Governing Diffusive Burning of Liquids, F. Res. Abs. and Rev., $1: 41-44$

[3] Gottuk, D., Scheffey, J., Williams, F., Gott, J., and Tabet, R., "Optical Fire Detection for Military Aircraft Hangars: Final Report on OFD Performance to Fuel Spill Fires and Optical Stresses," Naval Research Laboratory NRL/MR/6180 — 00-8457, Washington D.C., 2001, pp. 1-341.

[4] Putorti, A., "Flammable and Combustible Liquid Spill Burn Patterns," National Institute of Justice NIJ-604-00, 2001, pp. 1-55. 
[5] Mealy, C.L., Benfer, M.E., and Gottuk, D.T., "Fire Dynamics and Forensic Analysis of Liquid Fuel Fires," National Institute of Justice 2008-DN-BX-K168, 2010, pp.1-236.

[6] Gottuk, D., and White, D., "Liquid Fuel Fire," The SFPE Handbook of Fire Protection Engineering $\left(4^{\text {th }} e d\right)$, DiNenno P.J. (ed.), National Fire Protection Association, Quincy, MA 02269,2008, p.2/337.

[7] Babrauskas, V., (1983) Estimating Large Pool Fire Burning Rates, Fire Technology 19, 251-261, http://dx.doi.org/10.1007/BF02380810

[8] Babrauskas, V., "Heat Release Rates," The SFPE Handbook of Fire Protection Engineering $\left(4^{\text {th }} e d\right)$, DiNenno P.J. (ed.), National Fire Protection Association, Quincy, MA 02269, 2008, p $3 / 1$.

[9] United States Environmental Protection Agency - Compliance and Innovative Strategies Division, "Fuel Trends Report: Gasoline 1995-2005," Washington DC, 2008, pp.1-268.

[10] ASTM, "Standard Test Method for Heat and Visible Smoke Release Rates for Materials and Products Using an Oxygen Consumption Calorimeter, ASTM E1354," American Society for Testing and Materials, West Conshohocken, PA, 2009.

[11] Burgess, D., Zebatakis, M., "Research on the Hazards Associated with the Production and Handling of Liquid Nitrogen," Department of the Interior Bureau of Mines WADD TR 60141,1960 .

[12] Garo, J., Koseki, H., Vantelon, J., Fernandez-Pello, C., "Combustion of Liquid Fuels Floating on Water,” BIBLID: 0354-9836, 11, 2007, http://dx.doi.org/10.2298/TSCI0702119G 